\title{
Refill friction stir spot and resistance spot welding of aluminium joints with large total sheet thicknesses (III-1965-19)
}

\author{
Christopher Schmal $^{1}$ (D) $\cdot$ Gerson Meschut ${ }^{1}$
}

Received: 19 February 2020 / Accepted: 12 May 2020 / Published online: 30 May 2020

(C) The Author(s) 2020

\begin{abstract}
Refill friction stir spot welding (RFSSW) is a highly flexible and promising solid-state joining method for aluminium alloys. Alternatively, resistance spot welding (RSW) can be stated as an appropriate joining method which can be automated and used within a high-volume production due to short process times. Both processes do not need any additional elements and a flat surface on both sides of the joints can be realised. In order to meet the modern requirements for crash safety and structural stiffness, thermal and mechanical joining methods are mainly combined by using single-component epoxy resin adhesives. Due to an insufficient knowledge about the application of both thermal joining methods for the abovementioned material combinations combined with additional adhesives, deeper investigations were done regarding the interactions of the polymers and the joining processes. Starting with a brief presentation of the boundary conditions of the investigations and the refill friction stir spot welding and resistance spot welding of high-strength aluminium alloys with sheet thicknesses bigger than $5.8 \mathrm{~mm}$, the paper introduces the process-related joint properties of friction-based and resistance-based welded joints. Afterwards, the paper discusses the influences of the process parameter on the metallographic joint formation and load-bearing capacities for a selected two-sheet and four-sheet material combination. When combining the spot welding technologies with adhesives, the process parameters of the RFSSW process have to be adapted for the two-sheet combination by adding a squeeze-out step, while for RSW, just the preholding time has to be increased. Different challenges for both joining methods are shown. For RFSSW, the gap formation has to be considered when welding big total sheet thicknesses, while for RSW, the shape of the weld nugget is more important for an appropriate joint performance. Additionally, process optimisations for less adhesive incineration will be discussed for both joining processes, and the influences of the adhesive on the joint formation will be addressed with the help of load-bearing capacity evaluations. The paper closes with specific recommendations for the realisation of refill friction stir and resistance spot-welded joints with and without adhesive in the field of Al joints with big total sheet thicknesses which meet the quality demands and an outlook for further research steps will be given.
\end{abstract}

Keywords High-strength aluminium alloys · Thermal joining · Refill friction stir spot welding · Resistance spot welding · Destructive testing

\section{Introduction}

Using a B-pillar as an example, high-strength aluminium alloys (7075-T6, 6082-T6) offer a weight reduction of up to

Recommended for publication by Commission III - Resistance Welding, Solid State Welding, and Allied Joining Process

Christopher Schmal

Christopher.Schmal@1wf.upb.de; schmal@1wf.upb.de

1 Laboratory for Material and Joining Technology (LWF®), University of Paderborn, Paderborn, Germany
$40 \%$ but lead to higher total material thicknesses of up to $8.7 \mathrm{~mm}$ compared with high-strength steels (HCT780X/T and 22MnB5) [1]. These developments show that aluminium materials offer a high degree of lightweight construction potential and are even suitable for crash-relevant applications or for components subjected to cyclic stress, such as those used in automotive and aerospace engineering. In the aerospace industry, for example, $\mathrm{AlCu}$ alloys of the 2000 series with total material thicknesses of up to $8 \mathrm{~mm}$ are used to join fuselage segments to the outer skin [2]. Due to the sheet thicknesses used (in particular multi-sheet joints), the requirements for potential joining processes are also increasing at the same time. Adhesive bonding is a joining process that is suitable 
here in principle. It also contributes to increasing the strength of the material-optimised components. However, in order to ensure handling strength until the adhesive is cured, an additional joining process is required. According to the current state of the art, mechanical joining processes are used for bondings on aluminium thick-sheet applications (Figs. 1 and 2), which, however, reach their limits with higher strength aluminium grades (cf. [4]) due to high setting forces or deformations within the auxiliary joining elements.

Refill friction stir spot and resistance spot welding are possible alternatives in the field of thermal joining processes. In combination with adhesive, however, they can lead to adhesive burn-off in areas close to the welding spot and to impurities in the joining area (see, e.g. [5]). A further economic challenge when using refill friction stir spot welding is the heat input or cycle time. RFSSW requires low feed rates to enable sufficient plastification of the materials and optimum joint point formation. When using adhesives for both processes, it is important to minimise the energy input while at the same time a good joint formation in order to allow minimal adhesive damage for the highest possible bond strength is decisive.

Repeatable and appropriate joining of $\mathrm{Al}$ sheets with a big total sheet thickness is examined in more detail in this article. First, the two joining processes are presented and their processrelated special properties are discussed. Subsequently, the procedure for stable spot weld bonding is explained and the corresponding load-bearing capacities are compared for selected load cases.

\section{Introducing the joining processes and their joining task-specific properties}

\subsection{Refill friction stir spot welding process}

Refill friction stir spot welding (RFSSW) is based on the basic principle of friction stir welding (FSW) according to DIN EN ISO 25239, which is established especially in aircraft production. It is a two-sided friction-based process allowing spot- shaped joining of sheets. RFSSW uses a rotating tool consisting of a shoulder and a probe which generates a frictional heat input and, due to its axial counter-rotating tool movement, it mixes the material of the joining partner. Therewith, a media tight joint with a flat surface from both sides of the sheets is produced. Within the joining process, the sheets are clamped between the clamping ring and the anvil (see Fig. 1). The joint formation results in a high weld strength and a good load-bearing capacity, especially under lap shear load. RFSSW produces welds of high quality in difficult to weld materials [cf. 4].

The main advantages of this joining method are the following: because of the relatively low process temperature, excellent mechanical weld properties can be achieved, no pre-weld preparation or cleaning and no additional elements are needed, and a flat surface on both sides of the joint can be realised. In addition, RFSSW is a very flexible joining method concerning the sheet thicknesses and the combination of different sheet thicknesses in a two- or three-sheet setup [5]. In a very big thickness range (a package thickness of more than $8 \mathrm{~mm}$ ), it is possible to create appropriate joints with the same tool setup.

The principle applicability of the process for the aluminium alloy types considered in this paper has been investigated in many studies, for example, in [6] for EN AW-2024, in [5, 7] for EN AW-5xxx, in $[8,9]$ for EN AW-6181 and in $[6,10,11]$ for EN AW-7075. The effects of the adhesive in combination with larger sheet thicknesses $(>3 \mathrm{~mm}$ ) have not been considered in detail. Only [5] contained random tests with a heat curing crash-optimised epoxy resin adhesive. It was found that this was thermally degraded over a large area around the joining spot as a result of the heat effect and that the adhesive was present in the joining zone. It shows that the simple application of the process-specific process parameters to the spot weld bonding process in combination with adhesive is not easily possible.

\subsection{Resistance spot welding process}

Resistance spot welding (RSW) is a press welding process and represents a suitable alternative for joining $\mathrm{Al}$ alloys. A molten welding nugget is formed by the simultaneous application of an

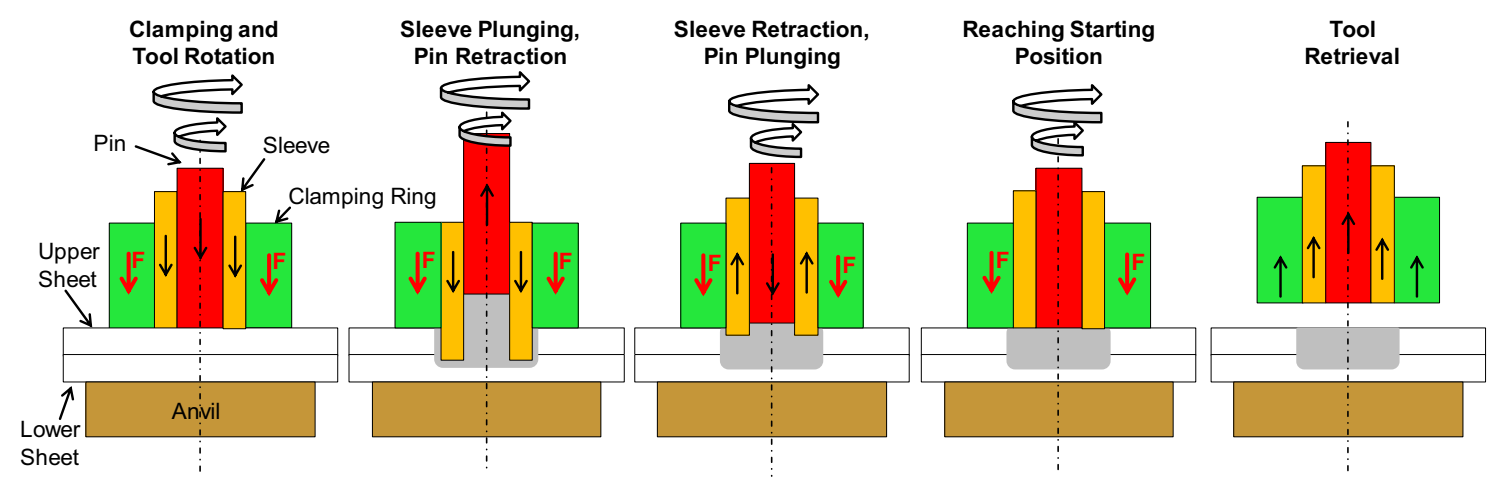

Fig. 1 Process steps of refill friction stir spot welding (RFSSW) [3] 

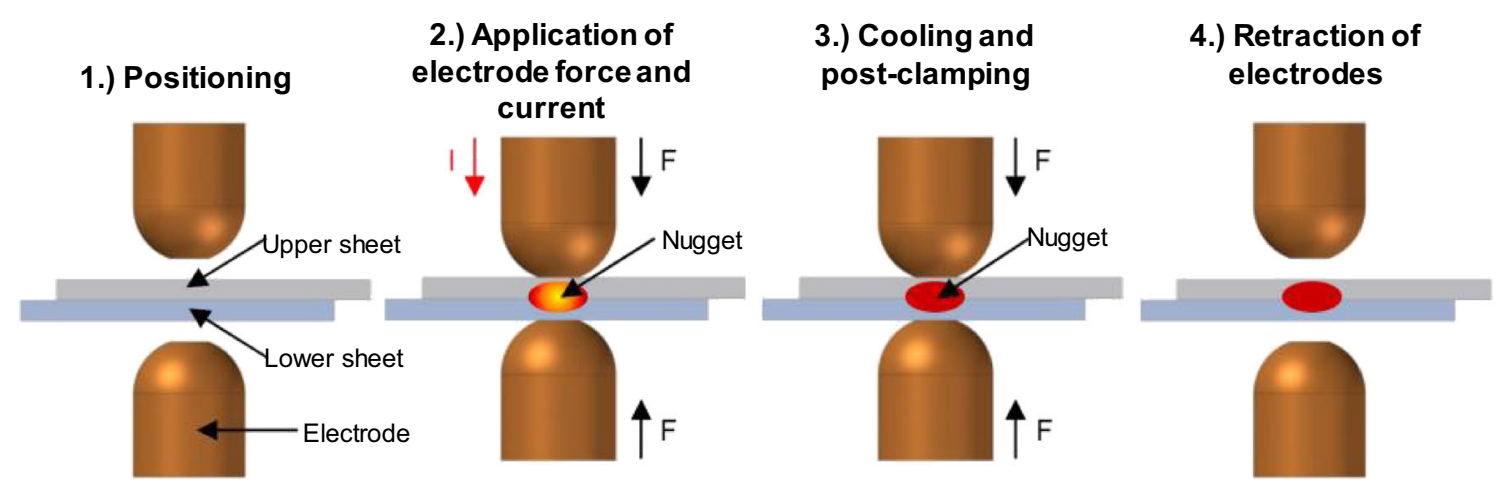

Fig. 2 Process steps of resistance spot welding (RSW)

electrode force and a welding current based on Joule's resistance heating between the joining partners (see Fig. 2). Due to short process times, adapted aluminium surfaces and electrical rod machining processes as well as the further development of control technology, the first large series applications in the thin-sheet metal area of car bodies (doors, lids) are already industrially established [12]. The current applications are focussing on well weldable 5000 and $6000 \mathrm{Al}$ alloys with material thicknesses of up to max. $2.5 \mathrm{~mm}$ in a double-sheet configuration. For material thicknesses with a minimum of $3.5 \mathrm{~mm}$, there are no process or standard specifications that allow the process to be qualified, e.g. DVS2932. Furthermore, there is insufficient process understanding for the joining task "high-strength thick plate $\mathrm{Al}$ alloys" (see DVS2932). In order to compensate the balance between heat input and heat dissipation, which occurs particularly early in the welding process due to the high thermal conductivity, short welding times in combination with high welding currents should be selected. To increase the welding quality, the use of current force programme is recommended in the DVS data sheet DVS 2932-3 as well as in [13-15]. In series applications, preconditioning currents are used to reduce contact resistances and improve early adhesive displacement by decreasing the adhesive viscosity. The existing problems regarding the alloying mechanism between the electrode caps and the surface of the parts to be joined have already been addressed in numerous studies $[16,17]$.

The process-related existence of a molten material can lead to metallurgical imperfections in the form of cracks and porosities. The formation of these imperfections can be observed in applications with particularly high currents due to extreme cooling and heating phases [18]. In resistance spot welding of aluminium with large material thicknesses, the adhesive also represents a significant disturbance factor. Despite the presence of local high component stiffnesses, the adhesive must be displaced in order to initiate the welding process. Insufficient adhesive displacement of higher-viscosity adhesives and sealants can lead to an increased tendency to spatter [14]. These welding spatters lead to a lack of process reproducibility and contamination of the surrounding component surfaces and thus to cost-intensive quality assurance and after-treatment of the component.

\section{Experimental procedure}

For the application of refill friction stir spot welding and resistance spot welding in the applications considered here, a systematic procedure is decisive, which is summarised below for both joining processes. After selecting a suitable tool set or suitable electrode caps, a stacking study (orientation of the sheets) is carried out, followed by a process parameter study in which the joint quality is first assessed with the aid of a chisel test according to DIN EN ISO 10447. A low-energy solution with fast tool movements and short tool dwell times or short current times is preferred for the purpose of minimising adhesive damage due to thermal decomposition processes. Especially when adding an adhesive, the range of suitable process parameters may be reduced and changed. After identification of one or more parameters, a deeper comparison may be necessary in which the mutual influence of the thermal and adhesive joining processes can be evaluated and optimum joining conditions can be determined. This is done, for example, with the aid of shear tensile tests according to DIN EN ISO 14273, in which the joint characteristics are indirectly analysed via the resulting load-bearing capacity. The application of the adhesive (adhesive bead with a diameter of $3 \mathrm{~mm}$ ) has been carried out in a reproducible way, so that a comparison of the different studies is possible. RFSSW trails have been performed with a Harms \& Wende GmbH \& Co. KG RPS100 machine while a $1000 \mathrm{~Hz}$ MFDC-welding machine equipped with a (NIMAK $\mathrm{GmbH}$ ) $\mathrm{C}$-Gun has been used for the RSW trails.

\section{Process parameter study for welding two-sheet aluminium joints with large total sheet thicknesses}

In this section, selected test results of the two-sheet combination consisting of medium- and high-strength $\mathrm{Al}$ alloys with a total sheet thickness of $5.8 \mathrm{~mm}$ are presented. For the material combination EN AW-5083 + EN AW-6082, results for refill friction stir spot welding as well as for resistance spot welding 
with and without adhesive are shown. In addition, the joint formation during resistance spot welding of the material combination is evaluated using the crack- and void-sensitive alloy EN AW-7075 instead of EN AW-6082. The abovementioned susceptibility to cracking and porosity exists in particular in the resistance spot welding process.

\subsection{Refill friction stir spot welding of two-sheet Al joints with and without additional adhesive}

Two tool sets (WZ12 and WZ17) are currently available from the manufacturer of the joining system. The tool set WZ17 with a probe diameter of $6.4 \mathrm{~mm}$ and a shoulder diameter of $9.0 \mathrm{~mm}$ was selected for all material combinations considered in this paper due to the big resulting available penetration depth range of up to $8.0 \mathrm{~mm}$. In preliminary investigations (chisel tests), the parameter set shown in Fig. 3 (top left) with $1500 \mathrm{rpm} \_1.5 \mathrm{~s} \_3.5 \mathrm{~mm} \_1.5 \mathrm{~s}$ was found to be the optimum. The limit between the plug fracture from the upper and lower joining partner was reached so that a very high degree of utilisation has been achieved. With the addition of the adhesive and by keeping the process parameters, undesirable brittle interfacial shear fractures occurred and thus insufficient joint spot formation (top left). The adhesive has to be squeezed-out of the joining area/shear layer to get appropriate joint properties. Therefore, approximately 16 different tool motion-based adhesive squeeze-out strategies were investigated, see also prior squeeze-out strategy [3], and tested with 3 repetitions for each solution approach. The variant shown in Fig. 3, in which the shoulder initially penetrates only $2.8 \mathrm{~mm}$, returns to a depth of $2 \mathrm{~mm}$ and then penetrates to the total penetration depth of $3.5 \mathrm{~mm}$, proved to be optimal and reproducible regarding the failure mode within the chisel test for 3 and more repetitions. The retraction stroke is carried out conventionally analogous to the parameter set without squeeze-out phase. The total process time increases by only $1.2 \mathrm{~s}$ due to the addition of the squeeze-out phase.

\subsection{Resistance spot welding of two-sheet Al joints with and without additional adhesive}

Based on $[14,19]$, the electrode caps and welding profiles were first defined. It was welded with the A0-20-R100 caps which are compatible with high electrode forces and with a welding profile which begins with a pre-pulse and ends with a downslope after the main current time. In order to keep the welding time as short as possible in which the heat flows into the components, the downslope was shortened by 320 to $80 \mathrm{~ms}$ in contrast to [14]. In order to reduce the maximum welding current below $50 \mathrm{kA}$, the main welding time which was used in [14] was extended by 120 to $180 \mathrm{~ms}$. The electrode force was set to a constant high force level of $8 \mathrm{kN}$ in order to facilitate simple process control. The weldability lobe diagram for resistance spot welding without adhesive shown in Fig. 4 shows a relatively large welding range from $I_{\min }=31$ $\mathrm{kA}$ to $I_{\max }=46 \mathrm{kA}$, in which welding spatters occurred.

Based on this study, the process parameters could be transferred directly to the application with adhesive (see Fig. 4). The initial contacting problem due to the insulating adhesive layer did not occur in this material combination, but the preholding time was increased to $500 \mathrm{~ms}$ to ensure better reproducibility. The size of the welding spots at $I_{\text {nenn }}=37$ kA remained almost constant directly above the boundary of $8.4 \mathrm{~mm}$ to the spot-welded joints, so the further investigations were carried out with this parameter set.
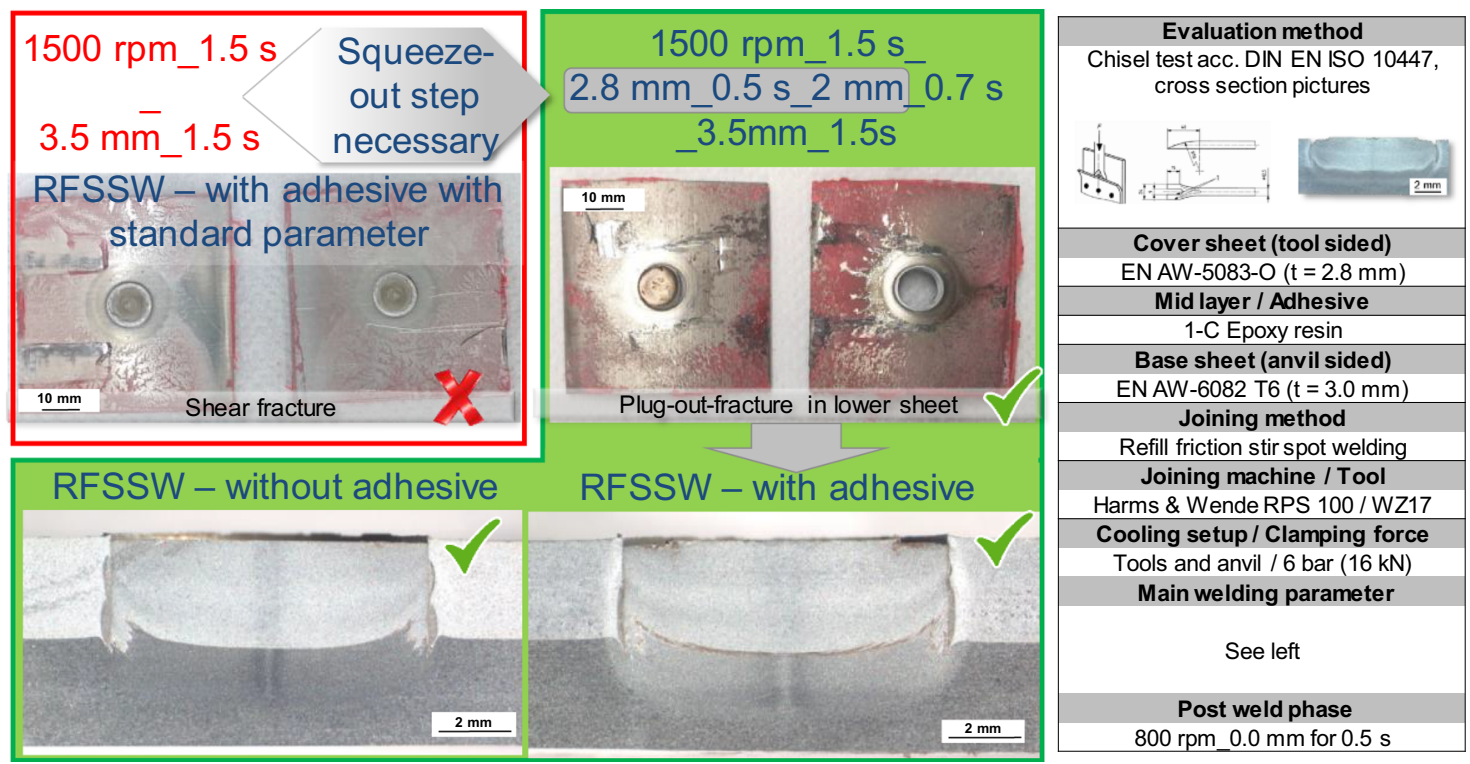

Fig. 3 RFSSW of EN AW-5083 and EN AW-6082 with additional adhesive: Welding with and without an additional squeeze-out step 


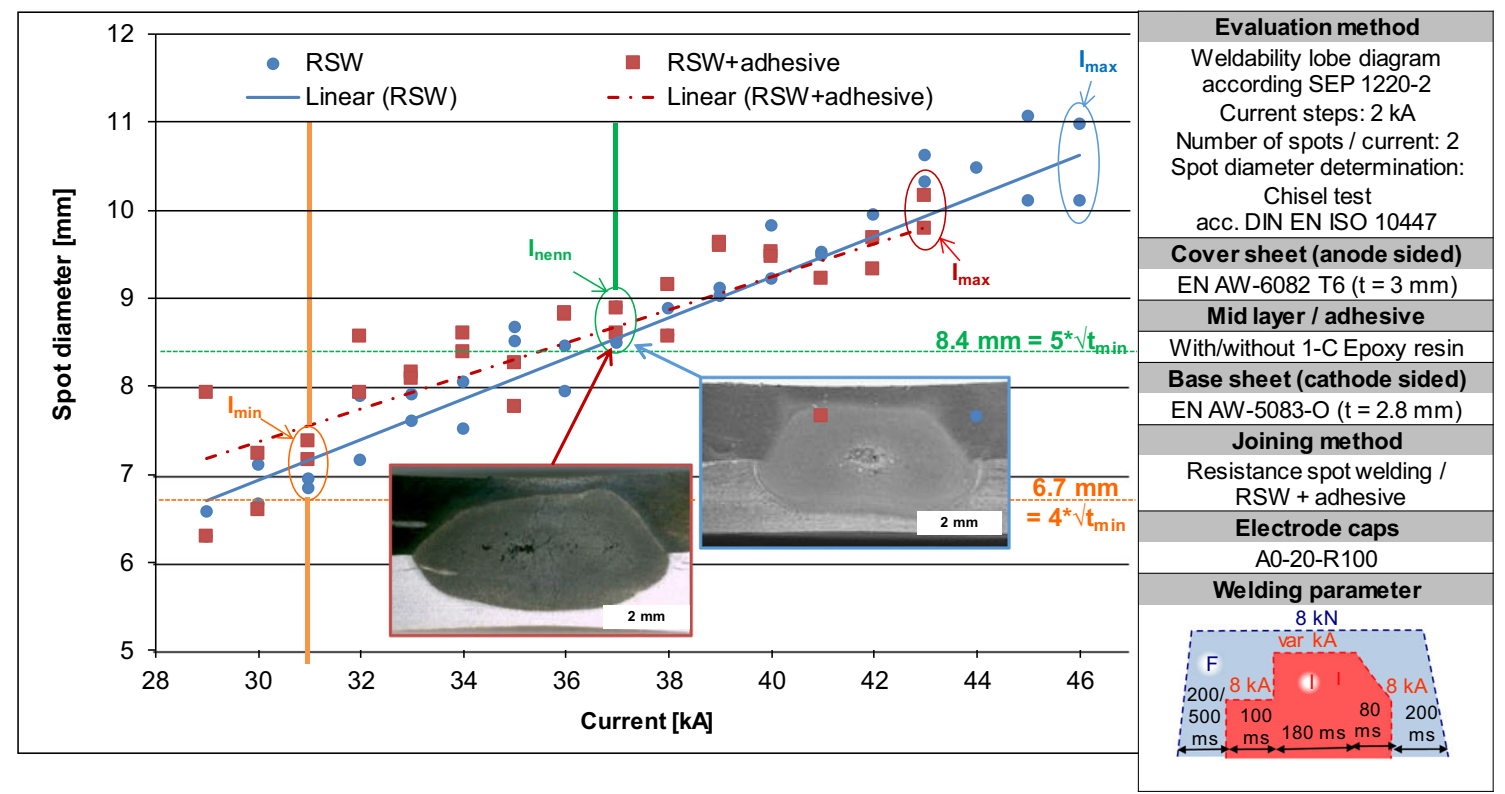

Fig. 4 RSW of EN AW-5083 and EN AW-6082: Weldability lobe diagram

\subsection{Comparison of resulting load-bearing capacities of welded two-sheet joints}

In order to analyse the mutual influence of the spot weld joint formation and the adhesive bond, the load-bearing properties were determined under quasistatic lap shear load of the bonded and thermally joined specimen as well as of the spot weld-bonded joints in the uncured and cured state (see Fig. 5). When comparing the load-bearing capacity of the spot-welded joints (b, c) with those which were joined and cured by spot welding with additional adhesive $(\mathrm{d}, \mathrm{e})$, it becomes clear that the additional adhesive has a minor (c vs. e) or negligible (b vs. d) influence on the formation of the spot weld. The influence of the spot welding processes on the adhesive joint is presented in the comparison between (a) and ( $\mathrm{f}$ ) and (a) and ( $\mathrm{g}$ ) respectively. The reason for this is the direct dependence of the maximum test loads on the adhesive bond, while the
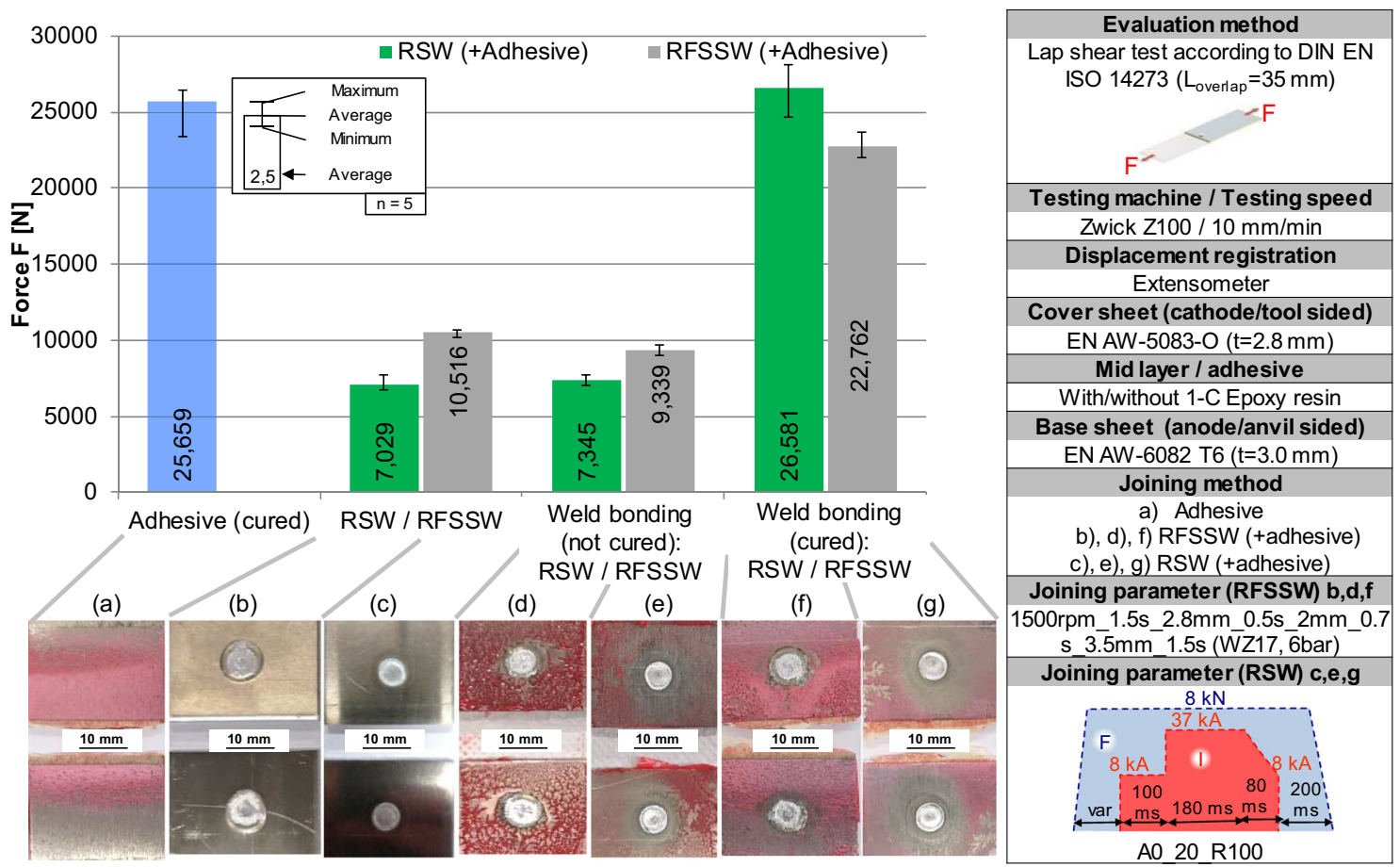

Fig. 5 Joining of EN AW-5083 and EN AW-6082: Comparison of maximum test forces under quasistatic lap shear load of adhesive-bonded, RSW (+adhesive) and RFSSW (+adhesive) specimen 
further failure behaviour of the spot welds may, under certain circumstances, be positively influenced with respect to energy absorption by ductile failure (not present in these investigations). In principle, it can be stated that the resistance spot welding process does not cause a reduction in maximum force even if the effective adhesive surface is reduced. On the other hand, the RFSSW process reduces the load-bearing capacity of the adhesive joint part (a) by approx. $12 \%$ to $22.76 \mathrm{kN}$ of the spot weldbonded joint. A combination of the process force (16 $\mathrm{kN}$ ), which is approx. twice as high for RFSSW, and the higher process temperatures in the area around the joint centre due to the longer process time (see also Chapter 5) will be responsible for this effect.

\subsection{Spot weld bonding of two-sheet Al joints with high-strength EN AW-7075 alloy}

In some publications, e.g. $[6,10,11,20]$, refill friction stir spot welding for application with the high-strength Al alloy EN AW-7075 has already been investigated successfully for the most part. However, challenges in resistance spot welding with EN AW-7075 are reported because of the tendency for hot cracking and heataffected zone (HAZ) softening [21]. In the following, a brief excursion into resistance spot welding bonding of the $\mathrm{AlZnMgCu} 1.5$ alloy in combination with the EN AW-5083 alloy which has already been considered in Chapter 4 is therefore given. EN AW-7075 was used in the same material thickness $(3.0 \mathrm{~mm})$ as EN AW-6082 in order to enable comparability with the test results of this material combination. Preliminary investigations (chisel tests and micrographs) showed that a direct transfer of the process parameters of the "Resistance spot welding of two-sheet Al joints with and without additional adhesive" section was possible. Figure 6 shows a comparison of the maximum test forces and energy absorption of elementally bonded, resistance spot-welded and spot weld-bonded specimens in the uncured and cured state. On average, all registered test loads are approx. $1 \mathrm{kN}$ above those produced with EN AW-6082 (Fig. 5). Even if the joint properties could not be directly exploited with the ratio of material tensile stresses (EN AW-6082 with about $342 \mathrm{~N} / \mathrm{mm}^{2}$ vs. EN AW-7075 with about $540 \mathrm{~N} /$ $\mathrm{mm}^{2}$ [22]), the results basically speak in favour of defect-free welds.

Despite the formation of minor porosities in the welding nugget, it can be assumed that good weldability exists at the boundary conditions described here. The scattering of the results of the spot weld-bonded and cured specimens (d) can be explained by the sporadic occurrence of welding spatters (see failure diagram).

\section{Process parameter study for welding four-sheet aluminium joints with large total sheet thicknesses}

In addition to the two-sheet joint with a total sheet thickness of $5.8 \mathrm{~mm}$ considered in the "Process parameter study for welding two-sheet aluminium joints with large total sheet thicknesses" section, this paper discusses refill FSSW and RSW of a four-sheet joint with a total sheet thickness of $9.3 \mathrm{~mm}$. Due to the big total sheet thickness with small individual sheet thicknesses, further problems arise, e.g. optimal sheet arrangement (stacking), appropriate adhesive displacement in all shear layers, gap development and optimal interconnection of all involved joining partners. In the following, selected test results for refill FSSW and RSW will be discussed.

\subsection{Refill friction stir spot welding of four-sheet Al joints}

An unfavourable characteristic of refill FSSW in connection with correspondingly large total sheet thicknesses is the development of gaps. In a flange situation, this leads to an affected adhesive bond due to air inclusions, etc. During energyintensive RFSSW of the four-sheet joint with a shoulder penetration depth of more than $6.3 \mathrm{~mm}$, due to the high process forces and strong deformations in the stirring zone, the joining partners may develop a global deformation (see, e.g. Fig. 7). The resulting deformations depend on the one hand on the sheet arrangement (stacking) and on the other hand on the joining parameters. In the following, exemplary microsections with variation of the sheet arrangement while retaining the process parameters are shown. On this basis, the arrangement variant was selected which led to the lowest deformations. The sheet with the greatest material thickness (EN AW-6082 $\mathrm{t}=3.0 \mathrm{~mm}$ ) was always arranged on the side of the weld to ensure the lowest possible welding penetration depth. In addition to low-energy input, this also reduces the tool load and tool wear.

The effective gaps were determined by means of a micrometre on each longitudinal side of the joint sample with five repetitions. Depending on the arrangement, average gap sizes of 0.3 to $0.91 \mathrm{~mm}$ were obtained. In addition, the loadbearing capacities were determined for selected arrangements in the critical lowest shear layer as well as in the highest shear layer. The tool-sided arrangement of the second largest sheet thickness (EN AW-5083 t=2.8 mm) was selected for the further parameter study. In this study, the influence of the process parameters at speeds of $1000 \mathrm{rpm}$ and $1500 \mathrm{rpm}$ and at different penetration depths of the shoulder was considered on the gap formation (Fig. 8). All parameter sets were empirically selected in such a way that, in order to minimise the process time and energy input, the highest possible workload 


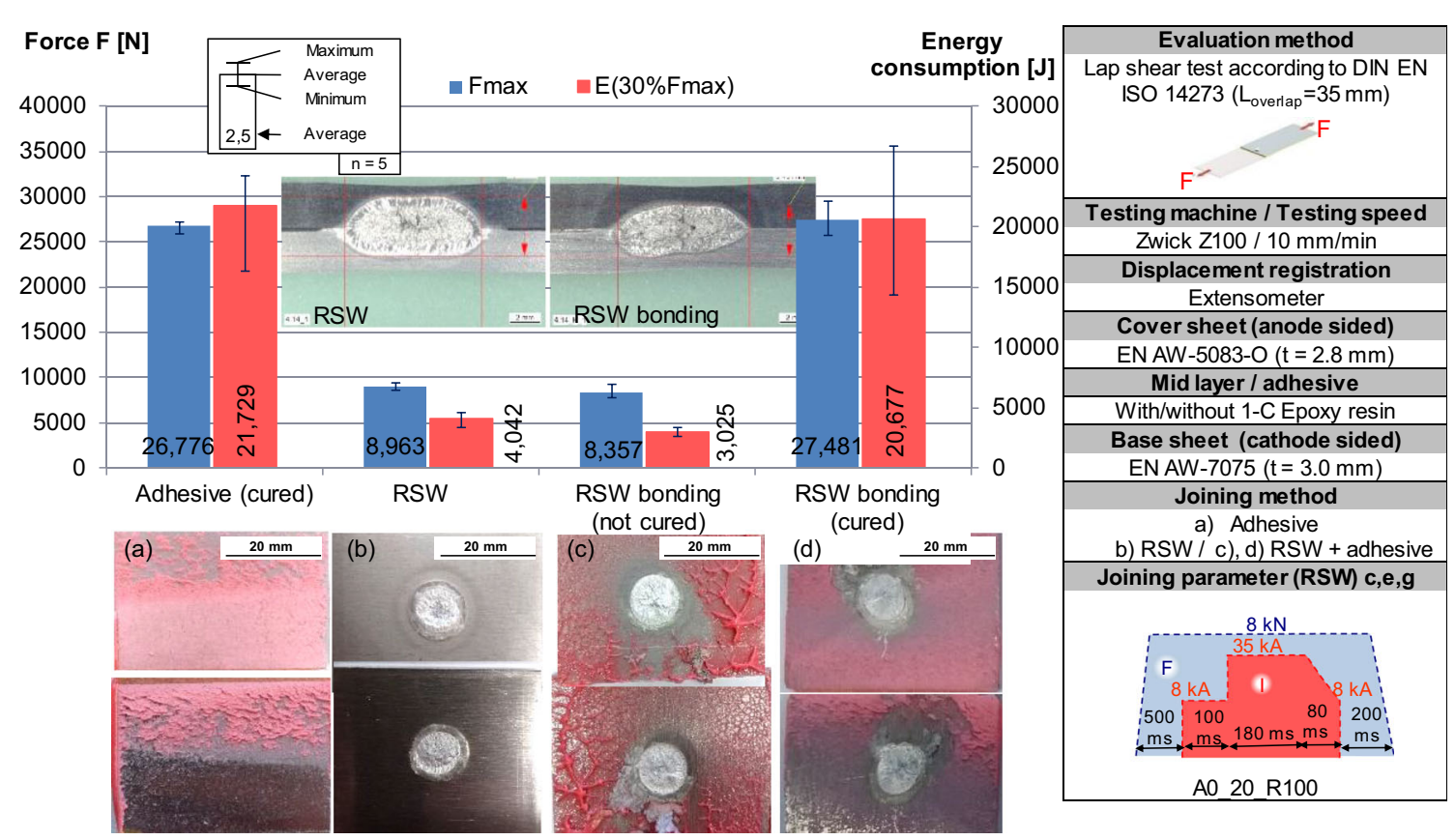

Fig. 6 RSW of EN AW-5083 and EN AW-7075: Comparison of resulting load-bearing capacities under quasistatic lap shear load of adhesive-bonded, RSW and RSW + adhesive specimen

of the drive motors of the joining system was achieved. Consequently, a longer welding time is necessary at low turning speeds as well as at greater penetration depths of the shoulder. In summary, it can be stated that a speed of $1500 \mathrm{rpm}$, almost independent of the penetration depth, enables the smallest gap development. In order to enable a stable formation of the joint with a sufficient welding depth and gaps smaller than $0.46 \mathrm{~mm}$, parameter sets $0 \_5$ and $0 \_6$ were selected for more detailed investigations.

In order to identify a suitable set of process parameters, shear tensile tests of the adhesive-bonded, RFSSW and spot weld- bonded joints were used and compared with both previously selected process parameters (see Fig. 9). The load was applied in the lowest shear layer or the critical shear layer with regard to the weld connection. In principle, a suitable joint formation was also possible without an additional squeeze-out phase (see test loads). The parameter set with a reduced welding depth (0_5) showed a lower spot strength (b and d vs. $c$ and e) compared with the parameter set with a welding depth increased by $0.3 \mathrm{~mm}\left(0 \_6\right)$. However, parameter set $0 \_5$ led to reduced adhesive damage and thus to a higher test load of the spot weldbonded and cured specimens (f vs. g).

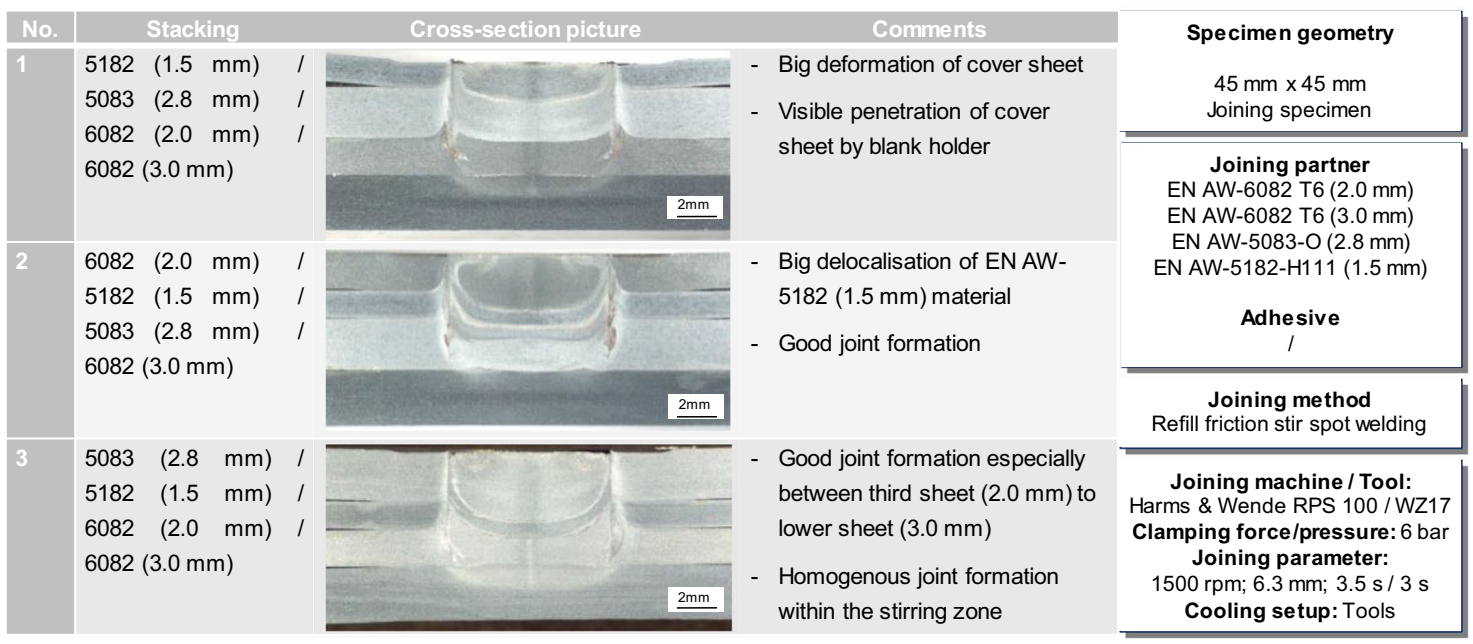

Fig. 7 RFSSW of EN AW-6082, EN AW-6082, EN AW-5083 and EN AW-5182: Cross-section pictures of joints welded in different orientations/ stacking setups with the thickest sheet on the anvil side 


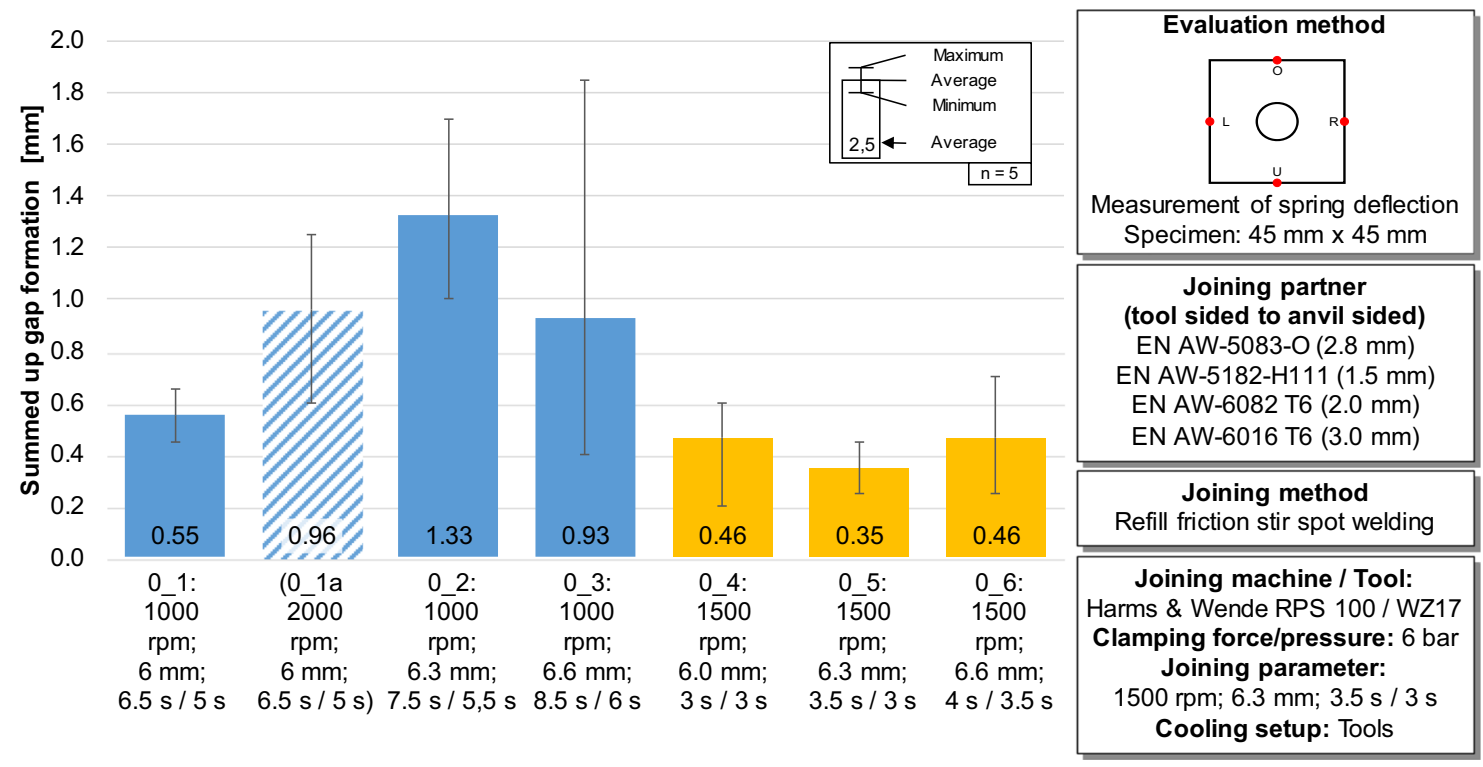

Fig. 8 RFSSW of EN AW-6082, EN AW-6082, EN AW-5083 and EN AW-5182: Comparison of summed-up gap formations for different process parameter sets welded with 1000 and $1500 \mathrm{rpm}$ (2000 rpm as a reference)

\subsection{Resistance spot welding of four-sheet Al joints}

In resistance spot welding of the four-sheet connection, the gap development is not regarded as a challenge, but rather a uniform bonding of all involved joining partners by an appropriately shaped welding nugget. In a first step, an arrangement study was carried out while retaining the process parameters and evaluating the welding nugget sizes in each shear layer (see Fig. 10). The arrangement variants were classified according to thickness, alloy type and Si content. Each variant was evaluated with both anode- and cathode-side orientation with two repetitions. Depending on the arrangement, either the hourglass-shaped (alloy type) or the oval (thickness, $\mathrm{Si}$ content) welding nugget formation was noticeable. In addition, it becomes clear that the 5XXXer alloy shows a significantly higher nugget growth, especially when arranged on the anode side, than the 6XXXer alloys used. By evaluating the respective nominal and actual nugget diameters related to the
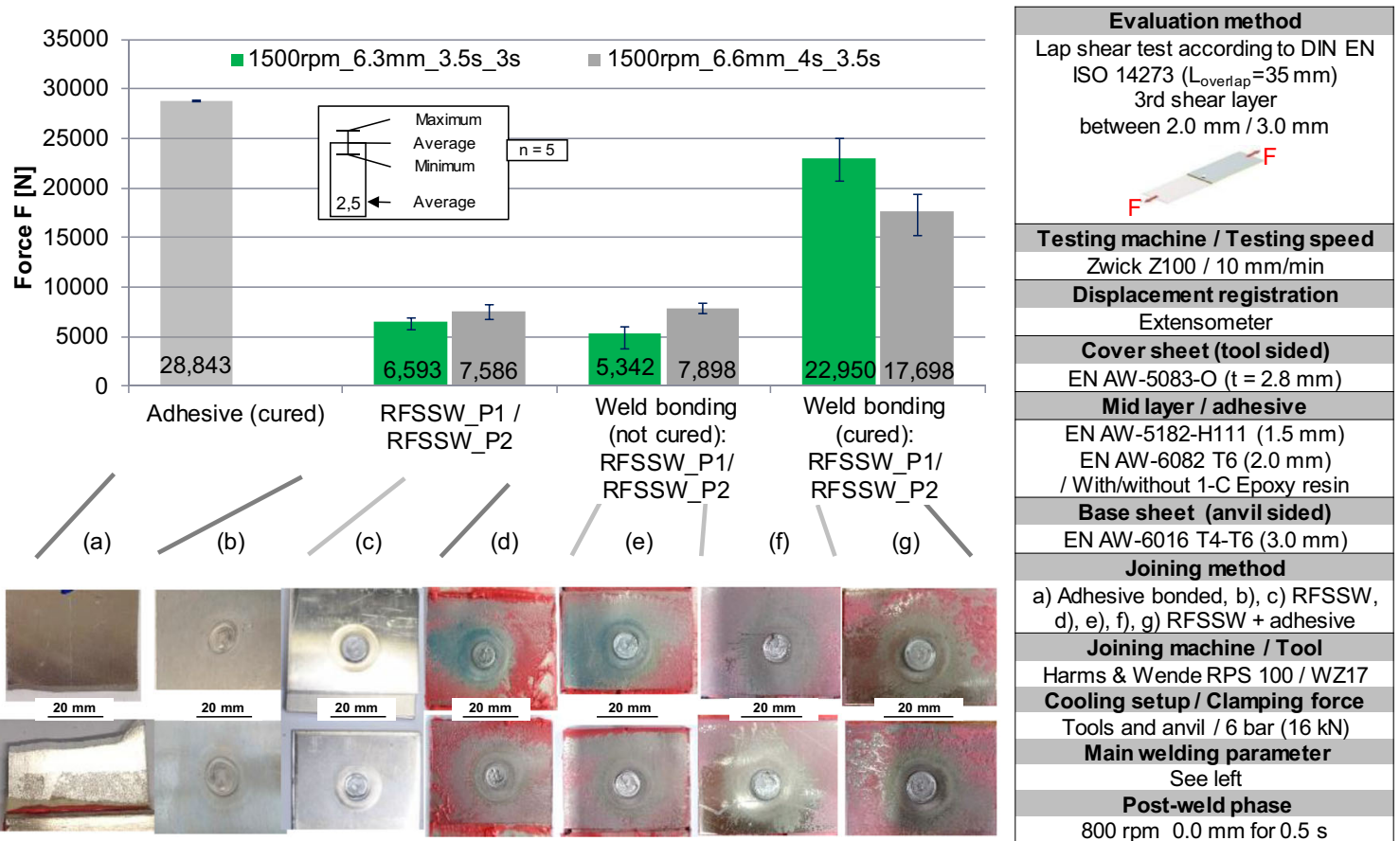

Fig. 9 RFSSW of EN AW-6082, EN AW-6082, EN AW-5083 and EN AW-5182: Comparison of resulting load-bearing capacity under quasistatic lap shear load for adhesive-bonded and with different process parameter (with and without curing) joined specimen 


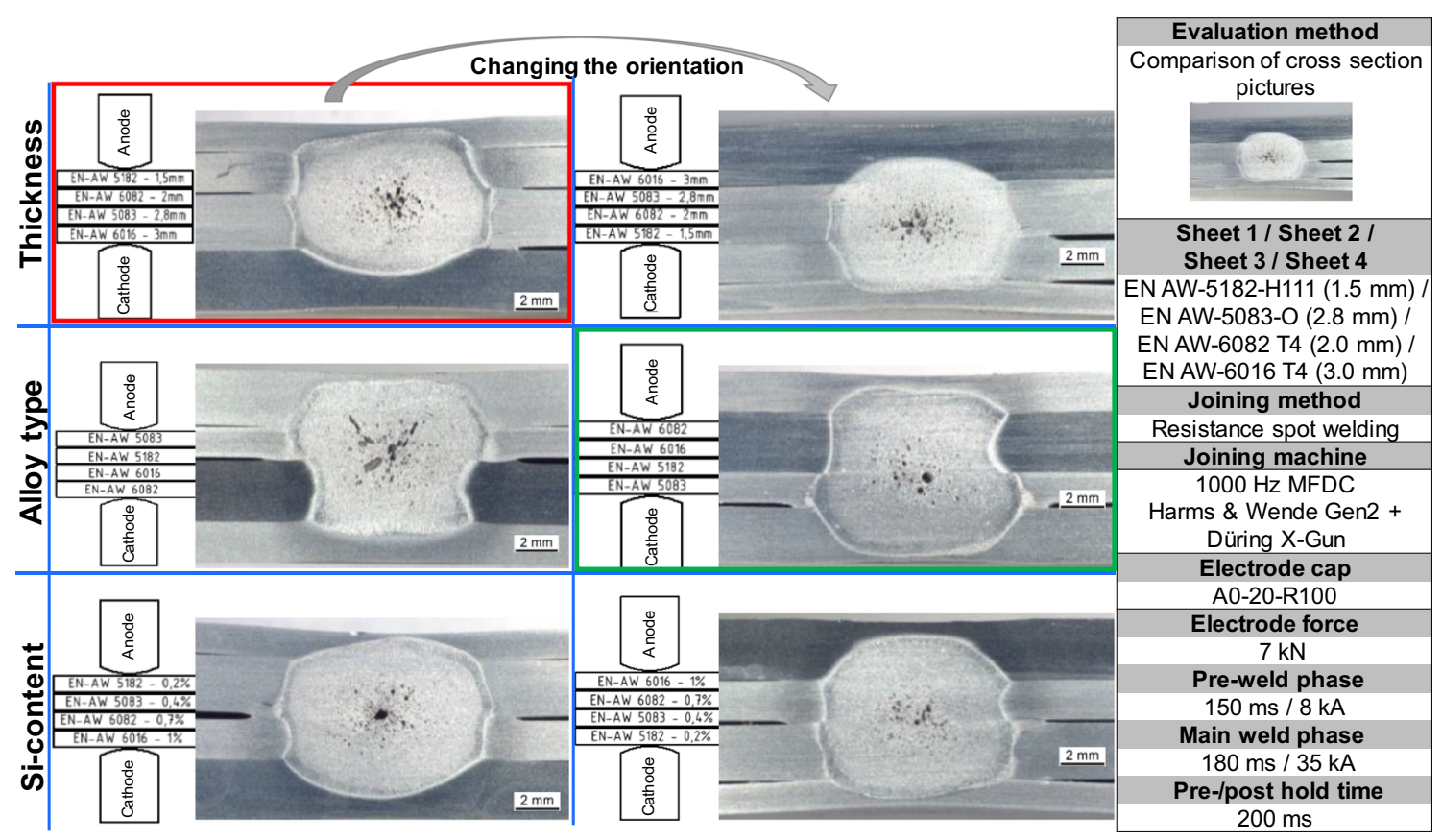

Fig. 10 RSW of EN AW-6082, EN AW-6082, EN AW-5083 and EN AW-5182: Cross-section pictures of joints welded in different orientations (regarding anode/cathode side) and stacking setups

shear plane, it was possible to identify the arrangement with the optimum interface to each joining partner. As a result, in the arrangement by alloy type with anode-side orientation of the $6 \mathrm{XXX}$ alloy, the welding nuggets in all layers were bigger than $130 \%$ of the nominal nugget diameter (see green frame). In comparison, a nugget that was $19 \%$ too small was measured in the lowest shear plane in the arrangement with the thinnest part on the anode side (see red frame).

Further investigations with adhesive showed that a reproducible and high-strength connection could be achieved by extending the holding time to $1000 \mathrm{~ms}$. Maximum welding currents of $34 \mathrm{kA}$ were sufficient to achieve the required $5 \mathrm{x}$ $\operatorname{root}(t)$ in all shear planes considered. The reduced adhesive surface was similarly small in all sheet metal planes with approx. $250-320 \mathrm{~mm}^{2}$.

\section{Conclusion}

In this work, refill friction stir spot welding and resistance spot welding were considered for a two-sheet joint with a total sheet thickness of $5.8 \mathrm{~mm}$ and a four-sheet combination with a total sheet thickness of $9.3 \mathrm{~mm}$ with and without additional structural adhesive. First, the specific characteristics were presented, and afterwards, the procedures for determining suitable process parameters and boundary conditions were discussed. Both sheet metal combinations with and without adhesive could be joined reproducibly and with high strength using both processes. The influence of the adhesive on the joint formation of the welding spots and the influence of the thermal joining process on the adhesive joint were examined. In RFSSW, a displacement phase in the conventional joining process (twosheet combination) was necessary for a reliable joining/ displacing of the adhesive from the joining zone, whereas in resistance spot welding, a good initial contacting of the joining partners and thus a good joint characteristic could be achieved by extending the preholding time. Thus, fixing strengths of the joint spots (determined by uncured shear tensile tests) of greater than $5.3 \mathrm{kN}$ and strengths of the cured spot weld-bonded joint in the range of the pure adhesive joint of $25 \mathrm{kN}$ could be achieved. Compared with resistance spot welding, RFSSW showed a bigger influence on the adhesive bond with regard to displacement or damage and also with regard to the resulting load-bearing capacity, but it can still be seen as an alternative process, not least due to the very flexible joint creation.

Investigations of the lifetime of RFSSW tools and the electrode caps are still pending. Within the scope of an industrial application, it would be necessary to decide individually which of the two robot-compatible joining processes has the greatest potential for use by taking the cycle times, the required joining properties and the lifetime of the tools respectively electrode caps into account.

Acknowledgements Open Access funding provided by Projekt DEAL. The research presented was performed in the context of the IGF project 19.434 of the research association of the DVS e.V. (German Welding Society), Aachener Str. 172, 40223 Düsseldorf, was funded by the AiF within the programme for the promotion of industrial joint research (IGF) by the Federal Ministry for Economic Affairs and Energy, based on a 
resolution of the Deutsche Bundestag. The authors gratefully thank these institutions for their support.

Open Access This article is licensed under a Creative Commons Attribution 4.0 International License, which permits use, sharing, adaptation, distribution and reproduction in any medium or format, as long as you give appropriate credit to the original author(s) and the source, provide a link to the Creative Commons licence, and indicate if changes were made. The images or other third party material in this article are included in the article's Creative Commons licence, unless indicated otherwise in a credit line to the material. If material is not included in the article's Creative Commons licence and your intended use is not permitted by statutory regulation or exceeds the permitted use, you will need to obtain permission directly from the copyright holder. To view a copy of this licence, visit http://creativecommons.org/licenses/by/4.0/.

\section{References}

1. Dörr J (2011) Semi-hot and hot forming of conventional and highstrength. Aluminium alloys; In: Forming in Car Body Engineering; ACI; Bad Nauheim

2. Rasche M, Syperek D. Zugscherfestigkeit nach DIN EN 1465 kein Kennwert zur Auswahl von Klebstoffen; Schweißen und Schneiden; 07/2015

3. Schmal C, Meschut G, Buhl N (2019) Joining of high strength aluminium alloys by refill friction stir spot welding (III-1854-18); Welding in the World (2019) 63:541-550; 10.1007/s40194-01800690-0

4. Chowdhurry SH, Chen DL, Bhole SD et al. (2013) Lap shear strength and fatigue behavior of friction stir spot welded dissimilar magnesium-to-aluminum joints with adhesive; In: Materials Science and Engineering: A, 2/2013; Vol. 25; pp. 53-60

5. Zech F, Cramer H, Appel L (2010) Reibpunktschweißen von Überlappverbindungen an Aluminiumknet- und -gusslegierungen im Vergleich; Final report of AiF-IGF-Project 15.317N. GSI SLV München, funded by the Ministry of Economics and Technology; Munich

6. Enkhsaikhan B, Shintaro F, Mitsuo F et al. (2019) Refill friction stir spot welding of surface-treated aerospace aluminum alloys with faying-surface sealant. In: Journal of Manufacturing Processes 04/ 2019, H. 42, S. 113-120

7. Tier MD, Rosendo TS, dos Santos JF et.al. (2013) The influence of refill FSSW parameters on the microstructure and shear strength of 5042 aluminium welds; In: Journal of Materials Processing Technology; Vol. 213; Iss. 6; pp. 997-1005

8. Rosendo T, Parra B, Tier M et al. (2011) Mechanical and microstructural investigation of friction spot welded AA6181-T4 aluminium alloy; In: Materials and Design; Vol. 32; pp. 1094-1100

9. Rosendo T, Tier M, Mazzaferro J et al. (2015) Mechanical performance of AA6181 refill friction spot welds under lap shear tensile loading; Fatigue \& Fracture Engineering Materials \& Structures; DOI: https://doi.org/10.1111/ffe.12312
10. Kubit A, Bucior M, Wydrzyński D, Trzepieciński T, Pytel M (2018) Failure mechanisms of refill friction stir spot welded 7075T6 aluminium alloy single-lap joints; Int J Adv Manuf Technol (The International Journal of Advanced Manufacturing Technology); 94/2018; No.: 9-12; 4479-4491; DOI: 10.1007/ s00170-017-1176-2

11. Kubit A, Wydrzynski D, Trzepiecinski T (2018) Refill friction stir spot welding of 7075-T6 aluminium alloy single-lap joints with polymer sealant interlayer. In: Composite Structures 201, S. 389 397. DOI: https://doi.org/10.1016/j.compstruct.2018.06.070

12. Knöller M (2014) Resistance spot welding of aluminium in the body shop of the new Mercedes-Benz C-Class; Proceedings of the Automotive Circle International Conference - Joining in Body-in-White 2014; 1st-3rd April 2014; Bad Nauheim; Germany

13. Dilthey U (2006) Schweißtechnische Fertigungsverfahren 1 Schweiß- und Schneidtechnologien; Springer-Verlag Berlin Heidelberg; 3. bearbeitete Auflage

14. Kunze S (2014) Beitrag zur Erhöhung der Prozesssicherheit beim Punktschweißen und Punktschweißkleben von Aluminium karosseriewerkstoffen; Dissertation; Universität Paderborn

15. Ostermann F (2007) Anwendungstechnologie Aluminium; 2nd newly edited and updated edition; Springer-Verlag; Berlin

16. Boomer DR, Hunter JA, Castle DR (2003) A new approach for robust high-productivity resistance spot welding of aluminium; Konferenz-Einzelbericht: SAE Paper 2003-01-0575; Detroit; pp. $81-94$

17. Schweißtechnische Lehr- und Versuchsanstalt SLV München: Entwicklung eines geeigneten Elektrodenbearbeitungsverfahrens für das Widerstandspunktschweißen von Aluminiumwerkstoffen; Final report; Deutscher Verband für Schweißen und verwandte Verfahren e.V. (DVS-Nr.: 04.047); funded by the AiF (IGF-Nr.: $16.096 \mathrm{~N}) ; 2011$

18. Zhang H, Senkara J (2012) Resistance welding fundamentals and applications; CRC Press; Boca Raton

19. Janzen V, Meschut G et.al. (2016) Einfluss von Punktdurchmesser, Fehlstellen und Imperfektionen auf das Festigkeitsverhalten von Aluminiumpunktschweiß-verbindungen; Final report IGF-No.: 17.789N; LWF-University of Paderborn

20. Martin O (2018) Research on the effect of the processing parameters on susceptibility of liquation cracking of $\mathrm{Al}$ alloys during refilled friction stir spot welding; ISBN: 9783319722832 ; Springer; Light metals

21. Feng Y, Luo Z, Li Y, Ling Z (2016) A novel method for resistance plug welding of 7075 aluminium alloy; Materials and Manufacturing Processes, 31/2016 No.: 16; 2077-2083; DOI: https://doi.org/10.1080/10426914.2015.1103853

22. AMCO Metall-Service GmbH; Technisches Datenblatt EN AW7075; https://amco-metall.de/fileadmin/downloads/Datenblaetter/ Datenblatt_AMCO_7075.pdf; Accessed 04. June 2019

Publisher's note Springer Nature remains neutral with regard to jurisdictional claims in published maps and institutional affiliations. 